\title{
Outcomes of hip and knee total joint arthroplasty in a Canadian inmate population over a 10-year period
}

\author{
Gavin Wood, MD \\ Sebastien Lalonde, MD CM \\ Kellen Walsh, MD \\ Kelly Harper, MD
}

Accepted Feb. 15, 2018

\author{
Correspondence to: \\ G. Wood \\ Department of Surgery \\ Queen's University \\ 76 Stuart St. \\ Kingston ON K7L2V7 \\ woodg@KGH.KARI.NET
}

DOI: $10.1503 /$ cjs.015117

\begin{abstract}
Background: Little information exists regarding the risk of complications in inmates who receive total hip or knee arthroplasties in Canada. Inmates tend to be less healthy owing to socioeconomic factors and an increased number of medical and psychiatric comorbidities. We compared revision and complication rates of total joint replacements in a cohort of incarcerated Canadians versus a cohort of non-inmates.
\end{abstract}

Methods: We obtained a list of all Canadian inmate inpatient hospital visits with diagnostic/procedure codes of primary hip or knee arthroplasty within the last 10 years from our institution's discharge abstract database. Demographic data and information related to the perioperative course, along with any data related to postoperative complications/readmissions, were obtained through manual chart review.

Results: The inmate group consisted of 20 men (mean age $58 \mathrm{yr}$ ) with a total of 24 primary total joint arthroplasties; the comparison group included 171 men (mean age $62 \mathrm{yr}$ ). Postoperatively, the inmates had a 4-fold increased risk of major complication compared with non-inmates $(33.3 \%$ v. $7.6 \%$; odds ratio $4.21, p=0.01)$. The inmates' revision rate was $20.8 \%$ compared with $5.8 \%$ in the comparison group ( $p=$ $0.03)$. The most common cause for revision in the inmate group was infection, with a rate of $16.7 \%$ compared with $3.5 \%$ in the comparison group ( $p=0.03$ ).

Conclusion: Patients requiring total joint arthroplasty who are inmates in the Canadian penitentiary system are at increased risk of complication and revision surgeries following total joint arthroplasty.

Contexte : Il y a peu de données concernant le risque de complications chez les détenus opérés pour une prothèse totale de la hanche ou du genou au Canada. Les détenus tendent à être en moins bonne santé en raison de divers facteurs socioéconomiques et d'un nombre accru de comorbidités médicales et psychiatriques. Nous avons comparé les taux de révision et de complications suite à des arthroplasties articulaires totales dans une cohorte de Canadiens incarcérés comparée à une cohorte d'individus non incarcérés.

Méthodes : Nous avons extrait de la base de données sur les congés des patients de notre établissement la liste de toutes les consultations de détenus hospitalisés assorties aux codes de diagnostics et d'interventions concernant les arthroplasties de la hanche ou du genou au cours des 10 dernières années. Les données démographiques et les renseignements relatifs à la période périopératoire, de même que les données concernant les complications postopératoires ou réadmissions ont été obtenus au moyen d'un examen manuel des dossiers.

Résultats : Le groupe de détenus se composait de 20 hommes (âgés en moyenne de 58 ans) totalisant 24 arthroplasties articulaires totales primaires; le groupe de comparaison incluait 171 hommes (âgés en moyenne de 62 ans). En période postopératoire, les détenus étaient exposés à un risque 4 fois plus élevé de complications majeures, comparativement aux individus non incarcérés (33,3\% c. 7,6\%; risque relatif 4,21, $p=0,01$ ). Le taux de révision chez les détenus a été de $20,8 \%$, contre $8 \%$ dans le groupe de comparaison $(p=0,03)$. La plus fréquente cause de révision chez les détenus était l'infection, avec un taux de $16,7 \%$, contre 3,5\% dans le groupe de comparaison $(p=0,03)$.

Conclusion : Les détenus des établissements carcéraux canadiens qui ont besoin d'une arthroplastie articulaire totale sont exposés à un risque accru de complications et de chirurgies de révision après leur intervention. 
T otal hip (THA) and total knee arthroplasties (TKA) are routinely performed worldwide for a variety of indications, making the careful monitoring and evaluation of their risks of considerable importance. Although identification and quantification of patientspecific risk factors are a priority reflected in the orthopedic literature, very little is known about the risk of complication in incarcerated individuals who receive a total hip or knee joint implant.

In 2015/16, there were 22956 adult offenders in the Canadian federal correction system. Approximately onethird of these inmates resided in custody in Ontario. ${ }^{1}$ Inmates represent an interesting patient subgroup, as they have characteristics that both distinguish them from the general population and present unique treatment considerations. Studies have shown that inmates are generally less healthy than their counterparts in the general population. ${ }^{2,3}$ Infectious diseases are especially common in Canadian prisons. The reported rate of HIV/AIDS in 2008 was $1.72 \%$, which is 10 times greater than the rate in the general population; the rate of hepatitis $\mathrm{C}$ was $30 \%$, which is 30 times greater than the rate in the general Canadian population; and the tuberculin skin test conversion rate was $12 \%$, which is 230 times greater than the rate in the general population. ${ }^{3-7}$ Canadian prisons have also been implicated as sites of methicillin-resistant Staphylococcus aureus (MRSA) outbreaks. ${ }^{8,9}$

There are several other factors that contribute to the poor health of the inmate population, including an increased rate of substance abuse, lifestyle risk factors and psychiatric comorbidities. ${ }^{2}$ There are also notably higher rates of mental illness among Canadian inmates than in the Canadian adult population..$^{10-12}$

The demographic characteristics of the inmate population differ from those of the general population in several notable ways. The prison population is younger than the general population, ${ }^{3} 90 \%$ of inmates are men, and Aboriginal Canadians are overrepresented in prison ${ }^{3,4}$ (they make up 2.3\% of the Canadian population ${ }^{1,5}$ ). Lower socioeconomic status also has a well-established link with incarceration. The prison population is less educated on average than the general Canadian population, with $55 \%$ of prisoners having not completed their highschool diploma. ${ }^{10}$ In addition, low income and homelessness are risk factors for imprisonment, ${ }^{3}$ as surveys have found that $19 \%$ of provincial inmates due for release were homeless before their incarceration. ${ }^{13}$

At present, very little is known about the effect of incarceration on patients undergoing total joint arthroplasty. Considering the specific health care challenges in this group, we hypothesize that they are at a significantly higher risk of complications and revision surgery. This study was performed to address the literature gap on this topic, and our primary aim was to compare the outcomes of TKA and THA in incarcerated patients compared with the non-incarcerated population.

\section{MethodS}

We performed a retrospective cohort study at our tertiary care academic centre and identified cases using our hospital information system. We obtained local ethics committee approval before data collection. This research did not receive any specific grant from funding agencies in the public, commercial, or not-for-profit sectors.

We searched our institution's discharge abstract database (DAD) to obtain a list of all inmate inpatient hospital visits with diagnostic/procedure codes pertaining to total joint arthroplasty within the last 10 years. Patients were included if they were an inmate of the correctional services of Canada at the time of surgery and excluded if they had a previous or active infection of the same joint at the time of surgery. A comparison group was created from a prospective database of male patients who underwent elective total hip or knee surgery for arthritis during the same time period and within the same academic hospital network. The minimum follow-up was 3 years for both groups.

We reviewed the electronic and paper charts and collected the demographic and outcome data pertinent to our study. These included age, body mass index (BMI), comorbidities resulting in a Charlson Comorbidity Index (CCI) score, American Society of Anesthesiologists (ASA) score, and HIV and hepatitis status. Additional information recorded included primary diagnosis, arthroplasty type, surgeon, skin to skin operative duration, length of stay in hospital, perioperative complications, hospital readmission and further procedures noted. Inmate patients received identical perioperative care to that of non-inmate patients, and resident/fellow involvement in the arthroplasty surgeries did not differ between groups.

\section{Statistical analysis}

Data were compiled using Excel and imported into IBM SPSS software for descriptive analysis. Statistical analyses included Mann-Whitney $U$, median, $\chi^{2}$ and independent $t$ tests for nonparametric and parametric data. We considered results to be significant at $p<0.05$.

\section{REsults}

The study group consisted of 20 male inmates who underwent a total of 24 primary total joint arthroplasties (11 hips and 13 knees) and 1 medial unicompartmental knee arthroplasty during the 10 -year study period. All total joint arthroplasties in the inmate group were performed for a diagnosis of osteoarthritis except for 1 THA that was performed for posttraumatic arthritis (4\%). The comparison group consisted of 171 male patients who underwent 102 THAs and 69 TKAs. The indication for surgery in the comparison group was predominantly osteoarthritis $(n=148,87 \%)$, followed by 
inflammatory arthropathies $(n=9,5 \%)$, osteonecrosis $(n=$ $7,4 \%)$ and posttraumatic arthritis $(n=3,2 \%$; Table 1$)$ The comparison group was significantly older (mean age 62 v. $58 \mathrm{yr}, p=0.03$ ) than the inmate group; the comparison group also had a lower BMI, but that difference did not reach statistical significance $(p=0.23)$. The median ASA and CCI scores were not significantly different; however, the rate of HIV/hepatitis $\mathrm{C}$ in the inmate population was significantly higher $(n=6[25 \%]$ v. $n=2$ $[1.2 \%], p=0.02)$. Finally, $25 \%(n=5)$ of the inmate group had diabetes mellitus (Table 1).

Table 1. Demographic and clinical characteristics of the study sample

\begin{tabular}{|c|c|c|c|}
\hline Characteristic & $\begin{array}{l}\text { Inmate group } \\
(n=24)\end{array}$ & $\begin{array}{l}\text { Comparison group } \\
\qquad(n=171)\end{array}$ & $p$ value \\
\hline \multicolumn{4}{|l|}{ Total sample } \\
\hline Age, yr; mean $\pm S D$ & $58 \pm 7.4$ & $62 \pm 7.2$ & 0.04 \\
\hline $\mathrm{BMI}$; mean $\pm \mathrm{SD}$ & $34 \pm 5.5$ & $32.4 \pm 6.3$ & 0.22 \\
\hline ASA score; median & 3 & 3 & 0.63 \\
\hline $\mathrm{CCl}$ score; median & 4 & 3 & 0.51 \\
\hline $\begin{array}{l}\text { HIV or hepatitis C; } \\
\text { no. }(\%)\end{array}$ & $6(25)$ & $2(1.2)$ & 0.01 \\
\hline LOS, $d ;$ mean \pm SD & $4.2 \pm 1.8$ & $3.6 \pm 1.9$ & 0.14 \\
\hline $\begin{array}{l}\text { Comorbidities; mean } \\
\pm \mathrm{SD}\end{array}$ & $5.5 \pm 3.9$ & $4.8 \pm 2.8$ & 0.31 \\
\hline $\begin{array}{l}\text { Duration of surgery, } \\
\text { min; mean } \pm S D\end{array}$ & $84 \pm 25$ & $68 \pm 20$ & 0.01 \\
\hline Infections; no. (\%) & $4(16.7)$ & $6(3.5)$ & 0.03 \\
\hline Revisions; no. (\%) & $5(20.8)$ & $10(5.8)$ & 0.03 \\
\hline \multicolumn{4}{|l|}{ Hip athroplasty } \\
\hline Age, yr; mean \pm SD & $59 \pm 7.7$ & $61 \pm 7.5$ & 0.37 \\
\hline $\mathrm{BMI}$; mean $\pm \mathrm{SD}$ & $32 \pm 4.7$ & $31 \pm 7.0$ & 0.68 \\
\hline ASA score; median & 3 & 3 & 0.98 \\
\hline $\mathrm{CCl}$ score; median & 4 & 3 & 0.25 \\
\hline $\begin{array}{l}\text { HIV or hepatitis C; } \\
\text { no. }(\%)\end{array}$ & $2(20)$ & $2(2)$ & 0.04 \\
\hline $\mathrm{LOS}, \mathrm{d}$; mean $\pm \mathrm{SD}$ & $4 \pm 1.6$ & $4 \pm 2.2$ & 0.37 \\
\hline $\begin{array}{l}\text { Comorbidities; mean } \\
\pm \mathrm{SD}\end{array}$ & $4.9 \pm 3.1$ & $4.6 \pm 2.7$ & 0.72 \\
\hline $\begin{array}{l}\text { Duration of surgery, } \\
\text { min; mean } \pm \text { SD }\end{array}$ & $84 \pm 22$ & $71 \pm 22$ & 0.08 \\
\hline Infections; no. (\%) & $1(9)$ & $4(4)$ & 0.40 \\
\hline Revisions; no. (\%) & 1 (9) & $4(4)$ & 0.40 \\
\hline \multicolumn{4}{|l|}{ Knee arthroplasty } \\
\hline Age, yr; mean \pm SD & $58 \pm 7.4$ & $63 \pm 6.8$ & 0.03 \\
\hline $\mathrm{BMl}$; mean $\pm \mathrm{SD}$ & $35 \pm 5.9$ & $33 \pm 4.7$ & 0.36 \\
\hline ASA score; median & 3 & 3 & 0.78 \\
\hline $\mathrm{CCl}$ score; median & 3 & 3 & 0.79 \\
\hline $\begin{array}{l}\text { HIV or hepatitis C; } \\
\text { no. }(\%)\end{array}$ & $4(29)$ & - & 0.01 \\
\hline $\mathrm{LOS}, \mathrm{d}$; mean $\pm \mathrm{SD}$ & $4 \pm 1.9$ & $3 \pm 1.1$ & 0.22 \\
\hline $\begin{array}{l}\text { Comorbidities; mean } \\
\pm \mathrm{SD}\end{array}$ & $5.9 \pm 4.5$ & $5.1 \pm 2.9$ & 0.58 \\
\hline $\begin{array}{l}\text { Duration of surgery, } \\
\text { min; mean } \pm S D\end{array}$ & $85 \pm 27$ & $63 \pm 17$ & 0.01 \\
\hline Infections; no. (\%) & $3(21)$ & $2(3)$ & 0.03 \\
\hline Revisions; no. (\%) & $4(28)$ & $6(9)$ & 0.04 \\
\hline
\end{tabular}

The TKAs and THAs in the inmate study group had a significantly longer duration of operation than those in the comparison group $(84.7 \pm 25 \mathrm{~min}$ v. $68.0 \pm 20 \mathrm{~min}, p=$ $0.01)$. This difference may be owing in part to the tendency toward a higher BMI in the inmate group as well as medical comorbidities and logistical challenges unique to the inmate group. The inmate group also spent longer on average in hospital after their operation than the comparison group (mean hospital stay $4.2 \pm 1.7 \mathrm{~d}$ v. $3.6 \pm 1.8 \mathrm{~d}, p=0.14$ ).

Postoperatively, the inmate cohort tended to fare worse than the comparison group. The inmates' major complication rate vastly exceeded that of the comparison group $(n=$ $8[33.3 \%]$ v. $n=13[7.6 \%]$, odds ratio [OR] 4.21, $p=0.01$; Table 2). The inmate group experienced 8 major complications (7 surgical and 1 medical); the comparison group experienced 13 major (12 surgical and 1 medical) and 9 minor complications.

The inmate group was found to have an almost 5 times greater likelihood of having an infection than the comparison group $(n=4$ [16.7\%] v. $n=6$ [3.5\%], OR 4.8, $p=0.03)$. When analyzed separately, only the TKA recipients were at a significantly increased risk of infection in the inmate group $(n=3[21 \%]$ v. $n=2[3 \%], p=0.03)$. The THAs in the inmate group showed a trend for an increased risk of infection, but this failed to reach significance $(n=1[9 \%] \mathrm{v}$. $n=4[4 \%] p=0.40$; Table 1). Of the postoperative infections that occurred in our study population, $75 \%(n=3)$ occurred within 35 days of the operation. Only 44\% $(n=4)$ of the infections in the comparison group occurred within this time frame. The 1 infection in the inmate group that occurred outside the 35-day window occurred 15 months after the index procedure.

The overall total joint revision rate was significantly higher in the inmate group than the comparison group $(n=$ 5 [20.8\%] v. $n=10$ [5.8\%], OR 3.6, $p=0.03)$. When analyzed separately, only the TKA recipients had a significantly higher revision rate in the inmate group $(n=4$ $[28 \%]$ v. $n=6[9 \%], p=0.04$; Table 1). This difference was both statistically and clinically relevant.

\section{Discussion}

In comparing the outcomes of THA and TKAs in our inmate cohort and patients in the general population, we were able to conclude that inmates are at significantly greater risk of requiring a revision surgery or experiencing a major complication related to the surgery. These findings were most prominent and statistically significant in the TKA subgroup. Therefore, we consider a patient's status as an incarcerated person to be a relevant consideration in determining a patient's operative candidacy and in preoperative planning.

The study population's reported rate of hepatitis C was in keeping with surveillance data estimates of $25 \%{ }^{4}$ Diabetes was overrepresented in our study population 


\begin{tabular}{|c|c|c|}
\hline Complication type & Inmate group $(n=24)$ & Comparison group $(n=171)$ \\
\hline Surgical & $\begin{array}{l}\text { Deep prosthetic infection }(n=3) \\
\text { Superficial infection }(n=1) \\
\text { Knee stiffness requiring manipulation }(n=1) \\
\text { Arthrofibrosis }(n=1) \\
\text { Late periprosthetic fracture }(n=1)\end{array}$ & $\begin{array}{l}\text { Deep prosthetic infection }(n=6) \\
\text { Dislocation }(n=3) \\
\text { Knee stiffness requiring manipulation }(n=3)\end{array}$ \\
\hline Medical (major) & ST-elevation myocardial infarction $(n=1)$ & Pulmonary embolism ( $n=1)$ \\
\hline Medical (minor) & None & $\begin{array}{l}\text { Urinary retention }(n=3) \\
\text { Transient hypotension }(n=2) \\
\text { Syncope }(n=1) \\
\text { Delirium }(n=1) \\
\text { Transient oxygen desaturation }(n=1) \\
\text { Symptomatic electrolyte abnormality }(n=1)\end{array}$ \\
\hline
\end{tabular}

compared with the general prison population $(30 \% \mathrm{v}$. $4.2 \%) .{ }^{2}$ Despite an increased rate of HIV/AIDS in the prison population $(1.2 \%)$, our data did not include any HIV-positive individuals. ${ }^{4}$

We found that inmates are 4.8 times more likely to experience a postoperative infection than a member of the general population. In contrast to the rate of $16.7 \%$ found among prisoners in this study, only $1.3 \%$ of all THA and TKA recipients in the general population go on to experience deep joint infections within a year of surgery. ${ }^{14,15}$ The implications of infections are clinically important, as more than one-quarter (26\%) of those who experience an infection in the year following their index procedure go on to require a revision surgery. ${ }^{14}$ In our study, infections accounted for more than half of the revision surgeries performed.

Our results show that inmates are 3.6 times more likely to require a revision surgery than the general population. This a relevant consideration owing to the increased operative difficulty of performing revision surgeries, the increased operative risk, the higher rate of complications as well as the greater cost associated with revision arthroplasties. ${ }^{16}$ In particular, revision arthroplasties performed for infections are associated with a longer operative duration, more blood loss and a higher rate of complications than those performed for aseptic loosening. ${ }^{17}$ As a result, revision TKAs and THAs performed for infections are more costly than those performed for all other indications except periprosthetic fracture. ${ }^{18}$

Although, to our knowledge, there are no prior studies examining the postoperative outcomes of total joint arthroplasties in inmates, our results show the impact that medical comorbidities and other risk factors, many of which are present in inmates, have on outcomes following total joint arthroplasty. Inmate populations have been shown to harbour a higher rate of medical conditions and risk factors, such as male status, smoking, IV drug use, alcohol use, diabetes, HIV infection, hepatitis C, liver cirrhosis and depression, that are associated with increased infection risk after total joint arthroplasty..$^{15,19-25}$ An accu- mulation of medical comorbidities, represented by the CCI score is associated with greater perioperative risk in patients receiving joint replacements. ${ }^{15}$

Characteristics inherent to the inmate population also predispose them to needing revision surgery. A systematic review of patient risk factors identified younger age and male sex as risk factors for revision. ${ }^{25}$ Although our inmate group was significantly younger than the comparison group, a mean difference of 4 years would not likely translate into a clinically significant difference. The fact that men have a 3-to 5-fold greater risk of joint revisions is particularly relevant since $90 \%$ of the prison population, and $100 \%$ of prison cohort in our study, is male. ${ }^{3,4,25}$ A distinguishing feature of our data is the significantly high rate of revision procedures performed in inmates for a diagnosis of infection. In our inmate group, more than half of revisions were performed for infection. In the general Canadian population, however, infection accounts for up only up to one-quarter of revision surgeries. ${ }^{26}$

\section{Limitations}

Study limitations include the small inmate sample size despite our institution's greater exposure to inmates because of our proximity to federal correctional institutions. Despite the smaller sample, the effect size was sufficient to detect a statistically significant difference in infection and revision rates in inmates compared with the comparison group. Another limitation is the potential loss to follow-up resulting from inmate transfers to other institutions or termination of sentence. Nevertheless, inmates in our group had a minimum 5-year follow-up with an average clinic return rate of $68 \%$.

\section{Conclusion}

Patients who are inmates in the Canadian penitentiary system are at increased risk of complications and revision surgery following THA or TKA. More research is needed 
to determine whether this represents an independent risk associated with incarceration, or whether it is merely a reflection of the constellation of previously identified risk factors espoused by the population.

Acknowledgement: The authors thank Heather Grant for her statistical analysis and manuscript support.

Affiliations: From the Department of Surgery, Queens University, Kingston, Ont. (Wood, Lalonde [at the time of writing], Walsh, Harper); and the Department of Orthopaedic Surgery, University of Missouri, Columbia, Mo. (Lalonde).

Competing interests: G. Wood has received payment and assistance for speakers fees and attending a conference to provide education unrelated to this article and for a company that provides competing products mentioned in this article. No other authors declared competing interests.

Contributors: S. Lalonde designed the study. S. Lalonde, K. Walsh and K. Harper acquired the data, which G. Wood, S. Lalonde and K. Walsh analyzed. S. Lalonde, K. Walsh and K. Harper wrote the article, which all authors reviewed and approved for publication.

\section{References}

1. Adult correctional statistics in Canada, 2015/2016. Statistics Canada; 2105. Available: www.statcan.gc.ca/pub/85-002-x/2015001/article/ 14163-eng.htm (accessed 2017 July 4).

2. Stewart LA, Nolan A, Sapers J, et al. Chronic health conditions reported by male inmates newly admitted to Canadian federal penitentiaries. CMA7 Open 2015;25:3:E97-102.

3. Kouyoumdjian F, Schuler A, Matheson F, et al. Health status of prisoners in Canada. Can Fam Physician 2016;62:215-22.

4. Infectious disease surveillance in Canadian federal penitentiaries 2007-2008. Correctional Service Canada; 2012. Available: www. csc-scc.gc.ca/text/pblct/infdscfp-2007-08/index-eng.shtml (accessed 2016 Mar. 22)

5. Profile of a Canadian offender. Correctional Service Canada; 2012 Available: www.csc-scc.gc.ca/publications/005007-3004-eng.shtml (accessed 2016 Mar. 22).

6. Tuberculosis prevention and control in Canada - a federal framework for action. Health Canada and the Public Health Agency of Canada; 2014. Available: http://epe.lac-bac.gc.ca/ 100/201/301/weekly_checklist/2014/internet/w14-25-U-E.html/ collections/collection_2014/aspc-phac/HP40-89-2013-eng.pdf (accessed 2016 Nov. 15).

7. Bouchard F. Health care needs assessment of federal inmates in Canada. Can 7 Public Health 2004;95:1-64.

8. Gilbert M. Outbreak in Alberta of community-acquired (USA300) methicillin-resistant Staphylococcus aureus in people with a history of drug use, homelessness or incarceration. CMA7 2006;175:149-54.

9. Main CL, Jayaratne P, Haley A, et al. Outbreaks of infection caused by community-acquired methicillin-resistant Staphylococcus aureus in a Canadian correctional facility. Can 7 Infect Dis Med Microbiol $2005 ; 16: 343-8$
10. CSC statistics - key facts and figures. Correctional Services Canada; 2014. Available: www.csc-scc.gc.ca/publications/005007-3024-eng. shtml (accessed 2016 Nov. 15).

11. Prevalence of mental health disorders among incoming federal offenders: Atlantic, Ontario, \& Pacific Regions. Correctional Services Canada; 2013. Available: www.csc-scc.gc.ca/research/005008 -err13-3-eng.shtml (accessed 2016 Nov. 12).

12. Usher A, Stewart L, Wilton G, et al. Profile and outcomes of male offenders with ADHD. Correctional Service of Canada; 2010. Available: www.csc-scc.gc.ca/research/005008-0226-01-eng.shtml (accessed 2016 Nov. 11).

13. Homeless and jailed: jailed and homeless. John Howard Society; 2010. Available: www.johnhoward.ca/document/JHS-Toronto \%20Report\%20Homeless\%20and\%20Jailed.pdf (accessed 2016 Nov. 11).

14. Bohm ER, Dunbar MJ, Frood JJ, et al. Rehospitalizations, early revisions, infections, and hospital resource use in the first year after hip and knee arthroplasties. 7 Arthroplasty 2012;27:232-7.

15. Rasouli MR, Restrepo C, Maltenfort MG, et al. Risk factors for surgical site infection following total joint arthroplasty. 7 Bone foint Surg Am 2014;96:e158-1-5.

16. Bozic KJ, Katz P, Cisternas M, et al. Hospital resource utilization for primary and revision total hip arthroplasty. 7 Bone foint Surg Am 2005; 87:570-6.

17. Bozic KJ, Ries MD. The impact of infection after total hip arthroplasty on hospital and surgeon resource utilization. 7 Bone foint Surg Am 2005;87:1746-51.

18. Kamath AF, Ong KL, Lau E, et al. Quantifying the burden of revision total joint arthroplasty for periprosthetic infection. 7 Arthroplasty 2015;30:1492-7.

19. Kong L, Cao J, Zhang Y, et al. Risk factors for periprosthetic joint infection following primary total hip or knee arthroplasty: a metaanalysis: risk factors for PJI following TJA. Int Wound 7 2017;14: 529-36.

20. Singh JA, Schleck C, Harmsen WS, et al. Current tobacco use is associated with higher rates of implant revision and deep infection after total hip or knee arthroplasty: a prospective cohort study. BMC Med 2015;13:283.

21. Maradit Kremers H, Kremers WK, Berry DJ, et al. Social and Behavioral Factors in Total Knee and Hip Arthroplasty. 7 Arthroplasty 2015;30:1852-4.

22. Lehman CR, Ries MD, Paiement GD, et al. Infection after total joint arthroplasty in patients with human immunodeficiency virus or intravenous drug use. 7 Arthroplasty 2001;16:330-5.

23. Pour AE, Matar WY, Jafari SM, et al. Total joint arthroplasty in patients with hepatitis C. F Bone foint Surg-Am 2011;93:1448-54.

24. Bozic KJ, Lau E, Kurtz S, et al. Patient-related risk factors for periprosthetic joint infection and postoperative mortality following total hip arthroplasty in Medicare patients. 7 Bone foint Surg-Am 2012; 94:794-800

25. Hawker GA, Glazier R, Mahomed NN, et al. Patient characteristics affecting the prognosis of total hip and knee joint arthroplasty: a systematic review. Can F Surg 2008;51:428.

26. Hip and knee replacements in canada: canadian joint replacement registry 2015 annual report. Canadian Institute for Health Information; 2015. 